\title{
Series Compensation of Self Excited Induction Generator Feeding Domestic Load
}

\author{
Anjali Gupta, Amit Tripathi, Rajneesh Kumar Pandey
}

\begin{abstract}
This paper presents a series compensated three phase self-excited induction generator feeding domestic load. This paper focus on the dynamic behaviour of Uncompensated SEIG and series compensated SEIG feeding dynamic load such as three phase induction motor. Various dynamic characteristic of SEIG feeding three phase induction motor is obtained by matlab/simulation and laboratory experimentation. The uncompensated and series compensated results is then compared to improve the voltage regulation of SEIG.
\end{abstract}

Index Terms-Dynamic load, self excited induction generator(SEIG),series-compensation.

\section{INTRODUCTION}

In modern world of globalization due to rapid increase in energy demand, most of the developing countries like India, china, Russia, Malaysia are shifting towards renewable energy resources from conventional energy resources[1]. Most of the fossil fuel causes large amount of air pollution causing dangerous to the life of human beings and aquatic animals. These fossil fuel are very limited in nature and require millions of years for the formation. Therefore, the developing countries which contain abundant of renewable energy resources moves from conventional energy resources to renewable energy resources[2][3].

One of the most popular renewable energy resource is hydro power plant energy. The hydro micro turbine can be coupled with Self excited induction generator to power the remote areas such as villages and hilly areas. In remote areas it is not feasible of extension of power grid so, for these types of places a mini hydro turbine can be coupled with the self excited induction generator to power the rural and hilly areas. The main advantages of using self excited induction generator with renewable energy resources are low cost, rugged construction, durable, less maintenance requirement and able to generate power at varying shaft speed [4],[5].The standalone self excited induction generator (SEIG) is capable of providing power to many agricultural loads and domestic loads. Self excitation in induction generator with fixed shunt capacitor bank at the stator terminal demonstrate the basic principle of SEIG [6],[7]. These fixed capacitor bank fails to provide good power quality when runs with the dynamic loads as these loads are not constant throughout the years.
Most of the agricultural and domestic loads are dynamic in nature like water pump, washing machine, flour mills etc. Due to these dynamic loads the power quality of the self excited induction generator is very poor. Hence various types of FACTS devices must be use in order to improve the power quality of standalone self excited induction generator (SEIG).

There are many different types of FACTS devices such as STATCOM,[8] static var compensator (SVC), Electronic load controller (ELC) and switched capacitor scheme[9]. These methods provide better power quality but are limited due to frequent maintenance requirement and high cost. Hence one of the cheapest and reliable method to provide better power quality is placing of series capacitor with the addition of fixed shunt capacitor bank in between the terminal of self excited induction and dynamic load. In this paper, the behaviour of series compensated self excited induction generator with three phase induction motor as a dynamic load is studied.[10] The experiment is performed in the laboratory with and without series compensation to observed the behaviour of SEIG and to obtain improved power quality of SEIG with series compensation. It is necessary to choose a specific value of series capacitor to improve power quality of SEIG otherwise improper value of series capacitor leads to harmonics and limits the speed of the dynamic loads[6].

\section{SYSTEM DESCRIPTION}

As shown in Fig.1 the self excited induction machine is feeding domestic load such as three phase induction motor. The SEIG consist of fixed shunt capacitor bank connected across the stator terminal of SEIG, prime mover driving SEIG, a dynamic load i.e. induction motor driven by SEIG and a series capacitor bank which is connected in between the terminals of SEIG and three phase SEIG.

Prime mover used in this experiment is a single phase 1450rpm, $8 \mathrm{amp}, 1.5 \mathrm{kw}, 440 \mathrm{v}$ dc shunt motor coupled with a three phase $1415 \mathrm{rpm}, 1.5 \mathrm{kw} 3 \mathrm{amp}, 440 \mathrm{v}$ self excited induction generator and electrically connected 3 phase $415 \mathrm{v}$ $1 \mathrm{kw}, 2 \mathrm{amp}$ induction motor. 


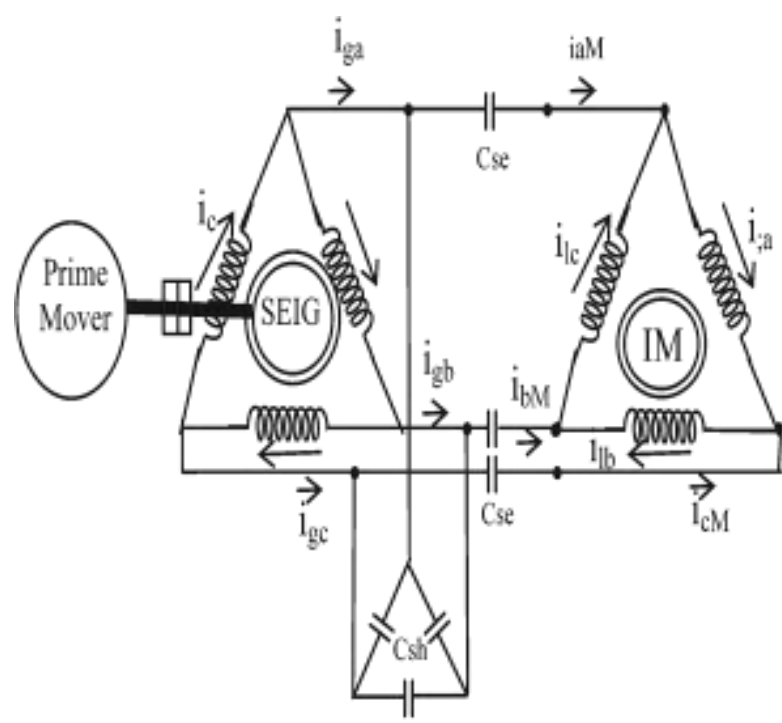

Fig.1.schematic picture of SEIG system with series compensation and IM load.

Designed self excited induction generator is driven by prime mover and shunt capacitor bank with some specific value is switched across the stator terminal in order to provide excitation and voltage built up at no load. To built up a voltage in SEIG there must be a suitable value of residual magnetism in the rotor. After the development of sufficient amount of residual magnetism in the rotor, SEIG gets excited and starts generating an electrical power.

Now, if induction motor is switched on directly with SEIG without any series compensation then a distorted and poor voltage waveform is produced and suddenly voltage of the motor collapses resulting shut down of induction motor. For successful starting, an induction motor must be connected with series compensation referred by fig. 1 .

\section{STATE SPACE MODELLING OF A SYSTEM}

State space modelling of SEIG requires the following;

1. Induction motor set 2. Series capacitor bank 3. Shunt capacitor bank A direct quadrature axis induction motor linkage model in the reference frame can be used for simulation in MATLAB for SEIG.

\section{i).Modelling of SEIG}

The state space model is simulated to solve the direct quadrature axis flux in the form of matrices and their respective $d-q$-axis currents and three-phase stator currents. The saturation in the SEIG is unified via relationship between magnetizing inductance $\left(L_{m}\right)$ versus magnetizing current $\left(I_{m}\right)$, obtained from the synchronous speed test of SEIG.

The $d$-q-axis flux state space model equations of an induction motor are described as [11][12]

$$
T_{e}=\frac{3}{4} P\left(\varphi_{d s} i_{q s}-\varphi_{q s} i_{d s}\right)
$$

The direct quadrature axis flux linkage can be expressed in terms of their respective currents as

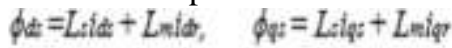

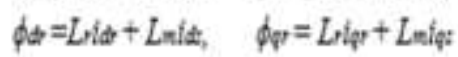

$$
\begin{aligned}
& L_{s}=L_{s}+L_{n}, \quad L_{r}=L_{n n}+L_{n}
\end{aligned}
$$

where $s, r, l$, and $m$ denote stator, rotor, leakage and magnetizing quantities, respectively in $d$-and $q$-axis.

\section{ii) Series Capacitor Modelling}

current flowing in motor $\left[I_{s M}\right]$ and series capacitors $\left[i_{s e}\right]$ are same. capacitive current $\left[i_{s e}\right]$ with the series capacitance $\left(C_{s e}\right)$ describe the voltage in series capacitor $\left[v_{s e}\right]$ that is given by

$$
C_{s e} p\left[v_{s e}\right]=\left[i_{s e}\right]=\left[i_{M}\right]
$$

Where

$$
\begin{aligned}
& {\left[I_{s M}\right]=\left[i i_{s} M \quad i_{q s} M\right] T} \\
& \text { and } \quad\left[v_{s e}\right]=\left[\begin{array}{ll}
v_{d s e} & v_{q q s e}
\end{array}\right] \text {. }
\end{aligned}
$$

The terminal voltage of motor is expressed as

$$
[v M]=[v d s M v q s M] T \quad[v M]=[v g-v s e] T
$$

iii) Induction Motor modelling

The induction motor is modelled by as a domestic load in the state space current form and in direct quadrature axis is given by

$$
\begin{aligned}
& p \phi_{d s}=v_{d s}-R s i d s \\
& p \phi_{q s}=v_{q s}-R s i q s \\
& p \phi_{d r}=v_{d r}-R_{r i} i_{i r}-\omega r \varphi_{q r} \\
& p \phi_{q r}=v_{q r}-R_{r i l q r}+\omega r \varphi d r
\end{aligned}
$$

$$
\text { where } \mid p=d / d t \text {. }
$$

The torque equation of induction generator is given by

$$
\left[v_{M}\right]=\left[R_{M}\right]\left[I_{M}\right]+\left[L_{M}\right] p\left[I_{M}\right]+\omega_{M}\left[G_{M}\right]\left[I_{M}\right] .
$$

Equation (13) is also expressed in terms of current derivative form as

$$
b\left[I_{M}\right]=\left[L_{M}\right]^{-1}\left\{\left[v_{M}\right]-\left[R_{M}\right]\left[I_{M}\right]-\omega_{M}\left[G_{M}\right]\left[I_{M}\right]\right\}(14)
$$

The torque equation is given as

$$
T_{L}=T_{e M}+J_{M}\left(2 / P_{M}\right) p \omega_{M} \cdot(14)
$$

The speed derivative of motor can be expressed as

$$
p\left[\omega_{M}\right]=\frac{P_{M}}{2 J_{M}}\left(T_{L}-T_{c M}\right)
$$

where $T_{L}=$ load torque, $J_{M}=$ moment of inertia, and $P_{M}=$ No. of poles in the induction motor. 


\section{EFFECT OF SERIES CAPACITANCE}

The entire experiment has been performed in laboratory which consist of fixed shunt compensator for self excitation of induction generator and an induction motor which is electrically connected through SEIG. The shunt capacitor of suitable rating is installed at the stator terminal of SEIG to provide self excitation. Similarly series compensated capacitor is connected in between the terminal of SEIG and induction motor to provide better voltage regulation.

When SEIG is switched on without series compensation, the induction motor acting as dynamic load is started for very a short period of time and after certain period, the voltage get collapse and motor is shut down[13]. When SEIG and induction motor set is switched on with series compensation, the induction motor is successfully started with improved voltage profile. The series compensation is simple and easy in construction which improves voltage regulation. It is require to select a proper value of series capacitor to avoid resonance phenomenon.[14]

\section{RESULTS AND CONCLUSION}

The dynamic performance obtained by MATLAB simulation and experimentation feeding the dynamic load such as three phase induction motor is given by Fig.2(a) and (b). For self excitation of SEIG a suitable value of shunt capacitor is connected at the terminal of stator.

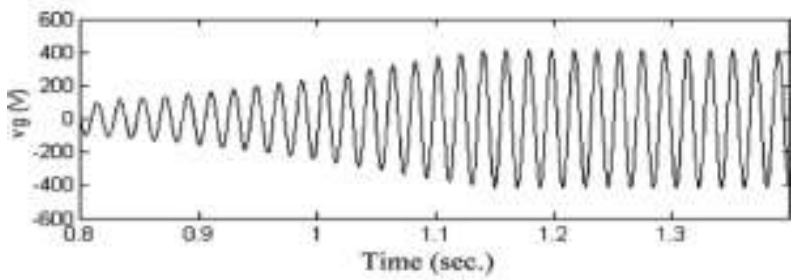

(a)

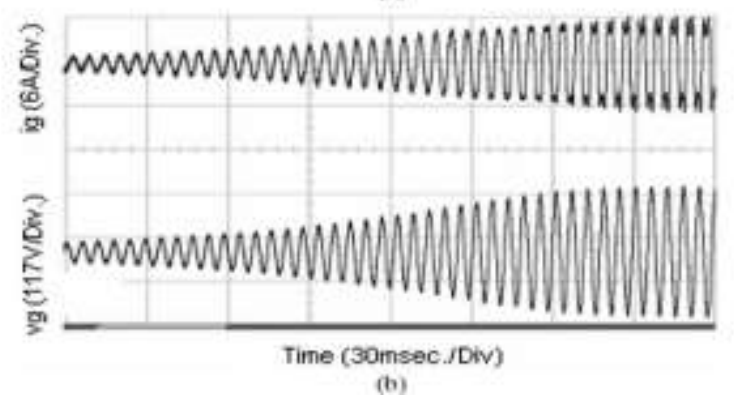

Fig. 2. (a) Simulated result of no load current and voltage of SEIG set.(b)Experimental result of no load current and voltage of SEIG set

When induction motor is started with SEIG in the absence of series compensation, the dynamic characteristics is formed. Fig. 3(a) shows the MATLAB simulation result of dynamic starting of induction motor without series compensation and Fig.3(b) represent experimentation result of dynamic starting of induction motor without series compensation. During starting of induction motor without series compensation, there occurs transient for a very few

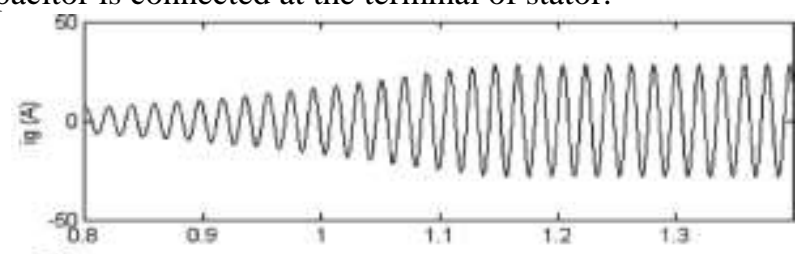

interval of time and due to this transient behaviour an induction motor shut down after a finite period of time. Therefore it is necessary to install series compensation for successful starting on induction motor.
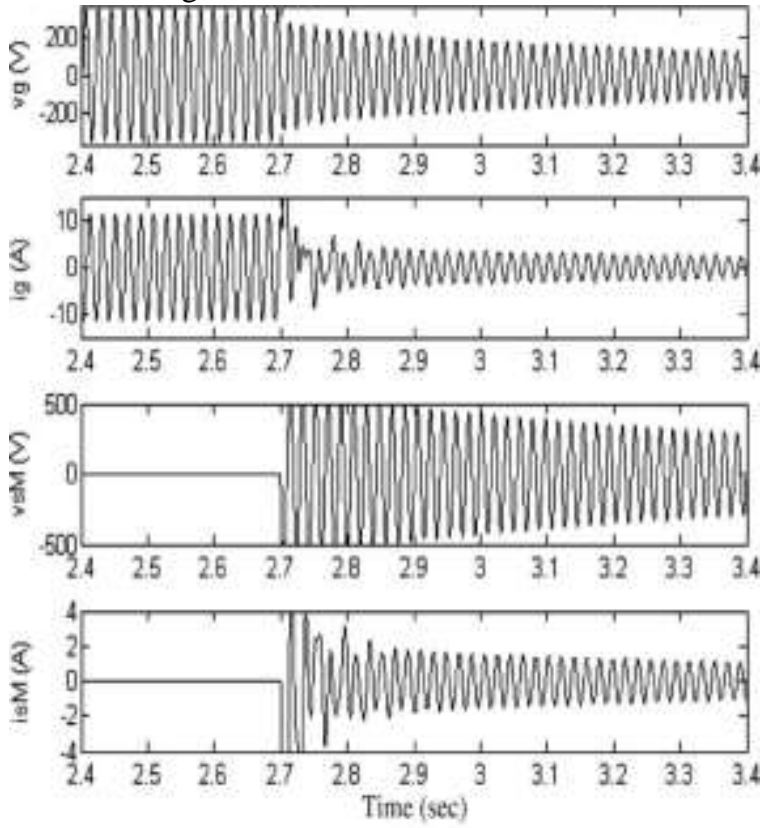

(a)

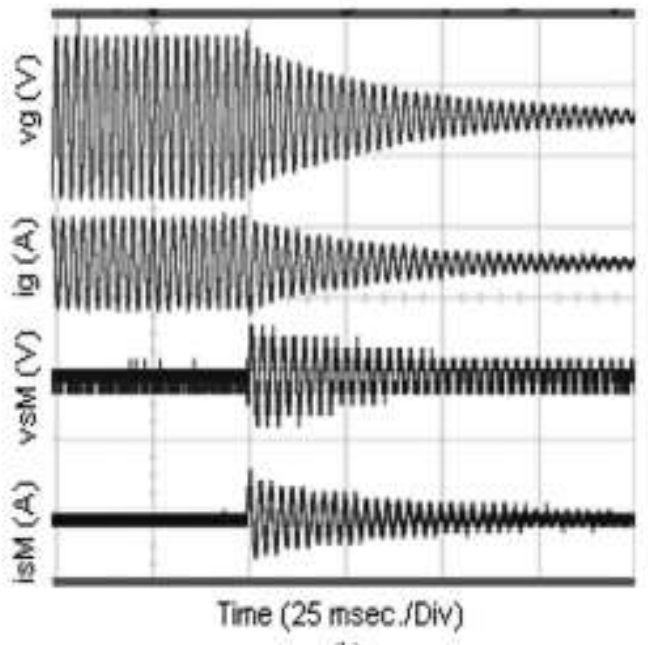

(b)

Fig. 3. (a) Simulation result of starting of SEIG-IM set without series compensation. (b) Experimental result of SEIG-IM set without series compensation.

Simulation result of starting three phase induction motor with series compensation is shown by fig. 4(a) and experimental result for the starting of three phase induction motor with series compensation is shown by fig. 4(b).

It is necessary to select a suitable value of series capacitor to avoid resonance in the motor. The resonance reduces the speed of the rotor due to which current and voltage also decreases.

Published By: 

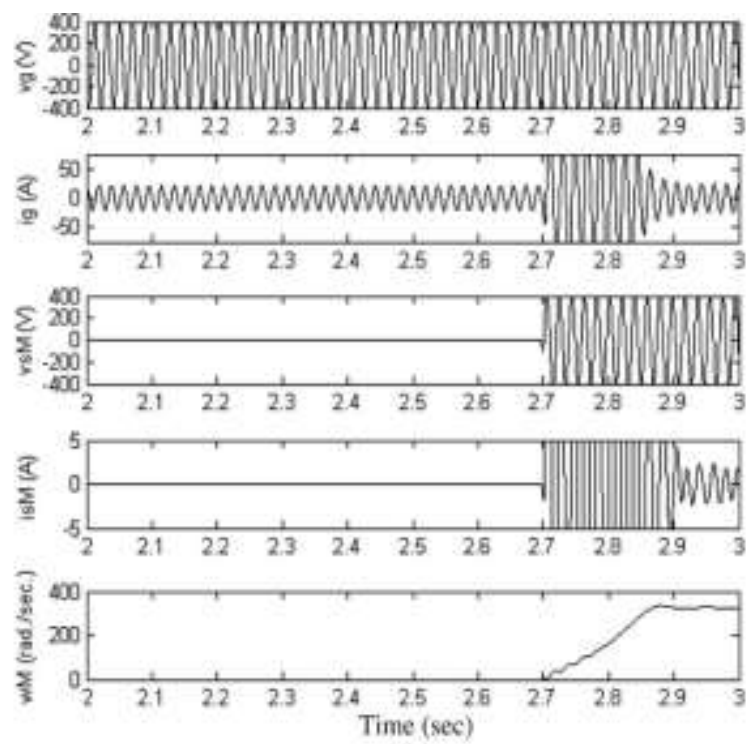

(a)

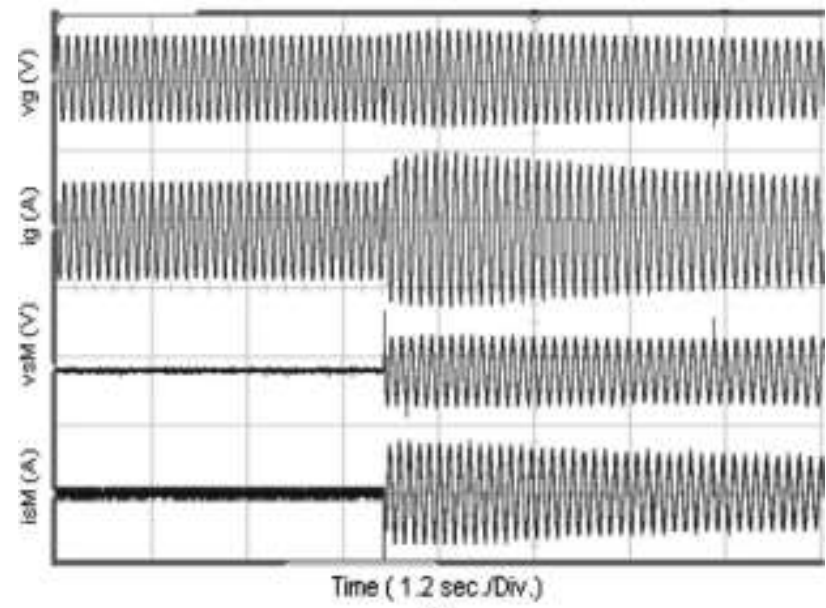

(b)

Fig. 4. (a) Simulation result of starting dynamics in SEIG induction motor set with series compensator. (b)

Experimental result of starting dynamics in SEIG induction motor set with series compensator.

\section{CONCLUSION}

During the study, the dynamic behavior of uncompensated three phase induction motor is compared with compensated three phase induction motor and the following result has been carried out by simulation and laboratory experiment-

1) Self excited induction generator is excited by placing suitable value of shunt capacitor at the stator terminal and the no load current and voltage waveform is shown by fig. 2(a) and (b)

2) When three phase induction motor and SEIG system is switched on without application of series compensation, the dynamic behavior waveform is formed which is shown by fig.3 (a) and (b).

3) When three phase induction motor and SEIG system is switched on with series compensation, an improved voltage regulation is formed which is shown by fig.4(a) and (b).

Therefore. from the comparison of uncompensated SEIG and series compensated SEIG results it is concluded that the voltage regulation of series compensated self excited induction generator feeding dynamic load has been improved.'

\section{REFERENCES}

1. National Renewable Energy Laboratory, "Renewable Electricity Futures Study,” 2012.

2. R. Lauge-Kristensen, "Renewable energy," in Sustainable Practices in the Built Environment, Second Edition, 2008.

3. N. L. Panwar, S. C. Kaushik, and S. Kothari, "Role of renewable energy sources in environmental protection: A review," Renewable and Sustainable Energy Reviews. 2011.

4. R. C. Bansal, "Three-phase self-excited induction generators: An overview," IEEE Transactions on Energy Conversion. 2005

5. G. K. Singh, "Self-excited induction generator research A survey," Electr. Power Syst. Res., 2004.

6. F. M. Potter, "Capacitive Excitation for Induction Generators," Trans. Am. Inst. Electr. Eng., 1935.

7. C. F. Wagner, "Self-Excitation of Induction Motors," Trans. Am. Inst. Electr. Eng., 1939.

8. M. S. El-Moursi, B. Bak-Jensen, and M. H Abdel-Rahman, "Novel STATCOM controller for mitigating SSR and damping power system oscillations in a series compensated wind park," IEEE Trans. Power Electron., 2010.

9. A. H. M. A. Rahim, M. Ahsanul Alam, and M. F. Kandlawala, "Dynamic performance improvement of an isolated wind turbine induction generator," Comput. Electr. Eng., 2009.

10. S. P. Singh, B. Singh, and M. P. Jain, "Comparative study on the performance of a commercially designed induction generator with induction motors operating as self excited induction generators," IEE Proc. C Gener. Transm. Distrib., 2010.

11. Analysis of Electric Machinery and Drive Systems. 2013.

12. L. Keviczky, R. Bars, J. Hetthéssy, and C. Bányász, "Introduction to MATLAB," Advanced Textbooks in Control and Signal Processing, 2019.

13. L. Varshney and R. K. Saket, "Reliability evaluation of SEIG rotor core magnetization with minimum capacitive excitation for unregulated renewable energy applications in remote areas," Ain Shams Eng. J., 2014.

14. Y. K. Chauhan, S. K. Jain, and B. Singh, "Operating performance of static series compensated three-phase self-excited induction generator," Int. J. Electr. Power Energy Syst., 2013. 